\title{
IS INTERNAL THORACIC ARTERY GRAFTING SUITABLE FOR A MODERATELY STENOTIC CORONARY ARTERY?
}

Michio Kawasuji, MD

Naoki Sakakibara, MD

Hirofumi Takemura, MD

Takeo Tedoriya, MD

Teruaki Ushijima, MD

Yoh Watanabe, MD
Grafting an internal thoracic artery to a coronary artery with moderate stenosis remains controversial. Competitive flow from the native coronary artery has been proposed as the cause of distal narrowing and ultimate failure of the internal thoracic artery graft. We investigated intraoperative phasic blood flow in internal thoracic arteries grafted to coronary arteries with various degrees of stenosis and the influence of stenosis on postoperative angiographic findings. One hundred patients who underwent coronary artery bypass grafting of an internal thoracic artery to the left anterior descending coronary artery were divided into three groups according to degree of coronary stenosis. Group 1 included 39 patients who had $75 \%$ or less stenosis, group 2 included 34 patients with stenosis from $76 \%$ to $90 \%$, and group 3 included 27 patients with stenosis greater than $90 \%$. Mean flow and peak systolic flow of internal thoracic artery graft in group 1 were lower than those in group $2(p<0.01, p<0.05)$. Peak diastolic flow in group 1 showed no difference from flows in groups 2 and 3 . In eight patients in group 1, internal thoracic artery flow showed a predominant diastolic peak with characteristic systolic reversal as a result of competitive flow from the native coronary artery. Angiography at 1 month showed that the internal thoracic artery graft was patent in every case. Relative contributions of native coronary artery and internal thoracic artery flow to distal perfusion differed among the three groups $(p<0.001$ ). In group $1,15 \%$ of patients showed native-dominant flow, $62 \%$ showed balanced flow, and $23 \%$ showed internal thoracic artery-dependent flow. In group 2,9\% of patients showed native-dominant flow, 29\% showed balanced flow, and $62 \%$ showed internal thoracic artery-dependent flow. In group $3,96 \%$ of patients showed internal thoracic artery-dependent flow. String sign of the internal thoracic artery graft developed in only three patients; in two of these patients internal thoracic arteries were grafted to coronary arteries with stenosis of $50 \%$ or less and in the other patient there was competitive flow from a diagonal vein graft. Eleven of 13 internal thoracic arteries grafted to coronary arteries with stenosis of $\mathbf{5 0 \%}$ or less did not show string sign. Competitive flow from a moderately stenotic coronary artery did not predispose the patient toward string sign of the internal thoracic artery graft in the presence of substantial diastolic internal thoracic artery flow. We conclude that internal thoracic artery grafting is acceptable for a moderately stenotic coronary artery. (J Thorac Cardiovasc Surg 1996;112:253-9)
From the Department of Surgery (I), Kanazawa University School of Medicine, Kanazawa, Japan.

Received for publication July 24, 1995; revisions requested Sept. 13, 1995; revisions received Nov. 7, 1995; accepted for publication Dec. 18, 1995.

Address for reprints: Michio Kawasuji, MD, Department of Surgery (I), Kanazawa University School of Medicine, Takaramachi 13-1, Kanazawa 920, Japan.

Copyright (C) 1996 by Mosby-Year Book, Inc.

$0022-5223 / 96 \$ 5.00+0 \quad \mathbf{1 2 / 1 / 7 1 2 5 6}$
Drogression of atherosclerosis in nongrafted coronary arteries adversely influences the long-term results of coronary artery bypass grafting (CABG). ${ }^{1}$ Atherosclerotic changes may progress not only with severe stenosis in coronary arteries but also in those with moderate stenosis. ${ }^{2}$ To improve the long-term results of $\mathrm{CABG}$ and reduce the need for reintervention, surgical indications have been extended to include coronary arteries with less than critical 
stenosis. ${ }^{3}$ The internal thoracic artery (ITA) is recognized as providing an excellent long-term patency rate. Use of the ITA as a bypass graft to the left anterior descending (LAD) coronary artery improves long-term survival after $\mathrm{CABG}^{4,5}$ and therefore is preferable whenever indicated. "String sign" or "distal thread phenomenon," angiographically described as diffuse distal narrowing of the ITA graft, has, however, been reported. ${ }^{6-8}$ High competitive flow from the native coronary artery with moderate stenosis has been proposed as the cause of reduced ITA graft flow and resulting ITA narrowing. ${ }^{6-9}$ Distal narrowing of the ITA graft has been attributed to medial necrosis and fibrosis as a result of ischemic injury caused by mobilization, ${ }^{6}$ spasm, ${ }^{10}$ and surrounding inflammation as occurs in postcardiotomy syndrome. ${ }^{11}$ On the other hand, experimental studies demonstrated that ITA graft flow was maintained at greater than in situ levels, even when the ITA was grafted to a completely patent coronary artery and both ITA graft and native coronary flow contributed to distal coronary perfusion, ${ }^{12,}{ }^{13}$ and it has been suggested that competitive flow may not be the cause of ITA narrowing. It remains controversial whether coronary arteries with moderate stenosis are suitable for ITA grafting. Although blood flow in the ITA grafted to coronary artery has a phasic property, the relationship between the hemodynamics of ITA grafts and postoperative angiographic findings have not been studied.

The purpose of this study was to investigate intraoperative hemodynamics of ITA grafts to LAD coronary arteries with various degrees of stenosis and to evaluate the influence of native coronary artery and ITA flows on the patency of ITA grafts.

\section{Material and methods}

One hundred patients who underwent elective CABG at Kanazawa University Medical Center were studied. Each patient received an ITA graft to the LAD artery and additional arterial or vein grafts to other coronary arteries. The patients ranged in age from 39 to 77 years, with a mean age of 62 years, and included 19 women and 81 men. Coronary arteries with $75 \%$ or more reduction in luminal diameter were considered to be significantly obstructed, but arteries with lesser degrees of obstruction were occasionally bypassed when operation was indicated for a substantial lesion in another vessel. Two of the patients had one-vessel disease, 22 had two-vessel disease, 47 had three-vessel disease, and 29 had had left main coronary artery disease. Fifty-four patients had a history of remote myocardial infarction documented by electrocardiographic changes, enzymatic changes, or bott. Left ventricular ejection fractions ranged from 0.30 to 0.85 (mean $0.58)$.
Preoperative ITA flow was measured by transthoracic duplex imaging combined with the pulsed Doppler method of computed sonography (SSH-160A; Toshiba Corp., Tokyo, Japan). ${ }^{14}$ The ITA was dissected with a pedicle from the first rib to the bifurcation into the superior epigastric and musculophrenic branches. Free flow from the distal cut end of the ITA was measured by the timed volumetric collection method after pharmacologic dilation by intraluminal injection of diluted papaverin chloride. The internal diameter of the ITA was measured with caliber probes in $0.5 \mathrm{~mm}$ gradations. $\mathrm{CABG}$ was performed with myocardial preservation by the administration of cold crystalloid potassium cardioplegic solution. All distal anastomoses were performed during a single period of aortic crossclamping. Patients received an average of 2.9 grafts each. The overall total was 288 grafts, including 116 ITAs, two right gastroepiploic arteries, and 170 saphenous vein grafts. Ninety-four left ITAs and six right ITAs were anastomosed to the LAD artery. The blood flow in the ITA graft was measured with a transit-time ultrasonic blood flowmeter (HT101; Transsonic Systems, Ithaca, N.Y.) after discontinuation of cardiopulmonary bypass. The transducer probe was fixed around the ITA graft at the beginning of the distal third portion. The ultrasonic field of the probe was filled with jelly to stabilize ultrasonic transmission and ensure that clear flow waves were displayed. The ITA did not have to be skeletonized for flow measurements. The ultrasonic transit-time theory works as follows: The transducers are positioned on one side of the vessel and the reflector bracket is situated midway between the two transducers on the opposite side of the vessel. The two transducers pass wide-beam ultrasonic signals back and forth, alternately intersecting the full area of the vessel twice on the pathway reflected by the acoustic reflector. The flowmeter then accurately measures the "transit time" required for the ultrasonic wave to travel from one transducer to the other. The difference between the upstream and downstream integrated transit times is a measure of volume flow. ${ }^{15}$ The ultrasonic transit-time flow meter system has several advantages, including direct metering of volume flow, nonconstrictive fit around the vessel, and zero baseline stability. Electrocardiograms and volume flow waves were recorded on a thermal-array recorder (RTA-1100; Nihon Kohden Corp., Tokyo, Japan).

The patients were divided into three groups according to degree of obstruction in either the left main or LAD coronary artery. The degree of coronary obstruction was determined with the edge-detection method (Cardio 500; Kontron Electronic AG, Eching, Germany) and was defined according to the classification of the American Heart Association Grading Committee. ${ }^{16}$ Group 1 included 39 patients who had moderate stenosis of the grafted coronary artery; 13 patients had $50 \%$ or less stenosis of the coronary artery, and 26 patients had from $51 \%$ to $75 \%$ stenosis of the coronary artery. Group 2 included 34 patients with coronary stenosis ranging from $76 \%$ to $90 \%$. Group 3 included 27 patients with coronary stenosis greater than $90 \%$. In group 1, 28 patients had stenosis in the LAD coronary artery and 11 patients had stenosis in the left main coronary artery. In group 2, 22 
Table I. Clinical characteristics of groups

\begin{tabular}{|c|c|c|c|c|c|c|}
\hline \multirow[b]{2}{*}{ Factor } & \multicolumn{2}{|c|}{$\begin{array}{l}\text { Group } 1 \\
(n=39)\end{array}$} & \multicolumn{2}{|c|}{$\begin{array}{l}\text { Group } 2 \\
(n=34)\end{array}$} & \multicolumn{2}{|c|}{$\begin{array}{l}\text { Group } 3 \\
(n=27)\end{array}$} \\
\hline & $\begin{array}{c}\text { No. } \\
\text { (or value) }\end{array}$ & $\%$ & $\begin{array}{c}\text { No. } \\
\text { (or value) }\end{array}$ & $\%$ & $\begin{array}{c}\text { No. } \\
\text { (or value) }\end{array}$ & $\%$ \\
\hline Age $(\mathrm{yr})$ & $61.9 \pm 1.3$ & & $63.1 \pm 1.3$ & & $60.1 \pm 1.7$ & \\
\hline Sex (male:female) & $27: 12$ & & $28: 6$ & & $26: 1$ & \\
\hline Body surface area $\left(\mathrm{m}^{2}\right)$ & $1.57 \pm 0.02$ & & $1.59 \pm 0.03$ & & $1.64 \pm 0.03$ & \\
\hline \multicolumn{7}{|l|}{ Coronary artery disease } \\
\hline One-vessel & 0 & 0 & 1 & 3 & 1 & 4 \\
\hline Two-vessel & 6 & 15 & 9 & 27 & 7 & 26 \\
\hline Three-vessel & 22 & 56 & 12 & 35 & 13 & 48 \\
\hline Left main & 11 & 28 & 12 & 35 & 6 & 22 \\
\hline Left ventricular ejection fraction & $0.58 \pm 0.02$ & & $0.58 \pm 0.02$ & & $0.57 \pm 0.03$ & \\
\hline Previous myocardial infarction & 19 & 49 & 20 & 59 & 15 & 56 \\
\hline Anterior myocardial infarction* & 1 & 3 & 10 & 29 & 11 & 41 \\
\hline
\end{tabular}

"Significant difference among the three groups; $p<0.01$.

patients had stenosis in the LAD coronary artery, six had stenosis in the left main coronary artery, and six had stenosis in both coronary arteries. In group 3, 21 patients had stenosis in the LAD coronary artery, one had left main coronary stenosis, and five had stenosis of both coronary arteries.

Selective coronary angiography was performed in each patient 1 month after operation. Coronary catheters with hand injection of low-osmolar radiographic contrast media were routinely used. According to the angiographic findings obtained from both native coronary artery and ITA injections, the pattern of relative contribution of the native LAD coronary artery and ITA graft to distal perfusion were classified into three categories: (1) dominant native coronary artery flow, (2) flow balanced between native coronary artery and ITA graft, and (3) flow dependent on ITA graft. String sign of the ITA was defined as diffuse distal narrowing, with a diameter less than $1.0 \mathrm{~mm}$.

Cumulative data were expressed as the mean \pm standard error of the mean. Statistical analysis was performed with Fisher's Exact Test, analysis of variance, and Scheffe's $F$ test to detect significant $(p<0.05)$ differences among measured variables.

\section{Results}

Clinical characteristics of the three groups are shown in Table I. There were no differences in age, sex, or body surface area among the three groups. There were also no differences in coronary artery disease, left ventricular ejection fraction, or history of myocardial infarction among the three groups. The incidence of anterior myocardial infarction in group 1 was significantly lower than those in the other groups $(p<0.005)$.

Volume flow waves of the ITA graft showed biphasic configurations and were classified into three types (Fig. 1). In type $A$, ITA flow showed a

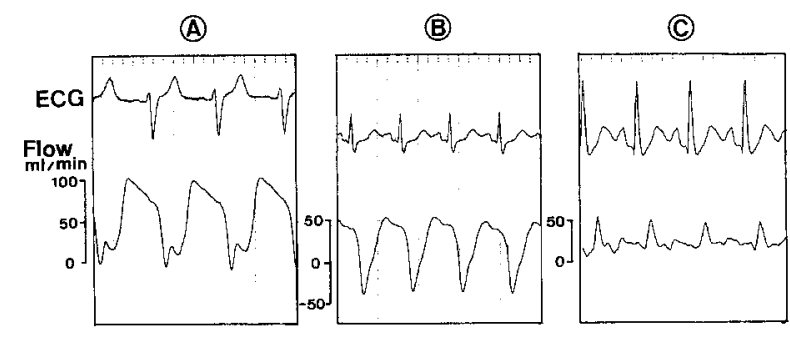

Fig. 1. Profiles of ITA graft flow. A, Predominantly diastolic flow, with peak systolic flow less than peak diastolic flow. B, Predominantly diastolic flow, with reversed systolic flow. C, Predominantly systolic flow, with peak systolic flow greater than peak diastolic flow. ECG, Electrocardiogram.

predominant diastolic peak and lower systolic peak. In type $B$, ITA flow showed a predominant diastolic peak and negative systolic flow; that is, a to-and-fro pattern. In type $C$, ITA flow showed a predominant systolic peak and lower diastolic peak. The distribution of flow wave profiles in the ITA graft is shown in Table II. In group 1, 31 patients (79\%) showed type A profile and eight patients (21\%) showed type $\mathrm{B}$ profile, but none of the patients showed type C profile. Eight of 13 patients with coronary stenosis of $50 \%$ or less showed type A profile, and the other five patients showed type B profile. In groups 2 and 3 , most of the patients showed type A profile. None of the patients in groups 2 and 3 showed type B profile. Four patients in groups 2 and 3 who showed type $\mathrm{C}$ profile had diffuse atherosclerosis of the LAD coronary artery on preoperative coronary angiography. There were significant differences in the 
Table II. Profiles of ITA graft flow

\begin{tabular}{|c|c|c|c|c|c|c|}
\hline \multirow{2}{*}{$\begin{array}{l}\text { Profile of ITA } \\
\text { graft flow }\end{array}$} & \multicolumn{2}{|c|}{$\begin{array}{l}\text { Group 1 } \\
(n=39)\end{array}$} & \multicolumn{2}{|c|}{$\begin{array}{l}\text { Group } 2 \\
(n=34)\end{array}$} & \multicolumn{2}{|c|}{$\begin{array}{l}\text { Group 3 } \\
(n=27)\end{array}$} \\
\hline & No. & $\%$ & No. & $\%$ & No. & $\%$ \\
\hline Type A & 31 & 79 & 33 & 97 & 24 & 89 \\
\hline Type B & 8 & 21 & 0 & 0 & 0 & 0 \\
\hline Type C & 0 & 0 & 1 & 3 & 3 & 11 \\
\hline
\end{tabular}

incidences of flow wave profiles among the three groups $(p<0.005)$.

ITA graft blood flow data are shown in Table III. Before operation, there was no difference in ITA flow among the three groups. During operation, there were no differences in luminal diameters of the LAD coronary artery or of the ITA graft among the three groups. There were no differences in the free flow from the cut end of the ITA graft among the three groups. Mean ITA flow in group 1 was significantly lower than that in group $2(p<0.01)$. Peak systolic ITA flow in group 1 was significantly lower than that in group $2(p<0.05)$. There were no significant differences in peak diastolic ITA flow among the three groups. The time-flow integral, which is the area between the flow curve and the zero baseline, was measured in systole and diastole with the peak of the $R$ wave and the end of $T$ wave on the electrocardiogram used as reference markers for systole. The ratio of the time-flow integral in diastole to the total time-flow integral in both systole and diastole was defined as the percentage diastolic fraction. Percentage diastolic fraction was $100 \%$ when the systolic time-flow integral was negative. Percentage diastolic fraction in group 1 was significantly greater than fractions in groups 2 and 3 $(p<0.01)$. This difference was the result of low or negative systolic flow in group 1.

Angiographic findings of the native coronary artery and ITA graft are shown in Table IV. All patients in the three groups showed a patent ITA graft, but two group 1 patients and one group 3 patient showed stenosis of $50 \%$ at the ITA anastomosis. Distal coronary artery flow showed three patterns: native-dominant flow, balanced flow, and ITA-dependent flow. The distribution of these three patterns differed significantly among the three groups $(p<0.001)$. Of 88 patients with a type A flow profile, 52 showed ITA-dependent flow, 31 showed balanced flow, and five showed native-dominant flow. In group 1, eight patients with type B flow profile revealed systolic reversal of contrast medium
Table III. Flow data of ITA grafts

\begin{tabular}{|c|c|c|c|}
\hline Factors & $\begin{array}{l}\text { Group 1 } \\
(n=39)\end{array}$ & $\begin{array}{l}\text { Group } 2 \\
(n=34)\end{array}$ & $\begin{array}{l}\text { Group } 3 \\
(n=27)\end{array}$ \\
\hline $\begin{array}{l}\text { Preoperative ITA } \\
\text { flow }(\mathrm{ml} / \mathrm{min})\end{array}$ & $46.8 \pm 3.2$ & $49.2 \pm 3.1$ & $50.6 \pm 4.0$ \\
\hline $\begin{array}{l}\text { Diameter of LAD } \\
\text { coronary artery } \\
(\mathrm{mm})\end{array}$ & $1.83 \pm 0.04$ & $1.81 \pm 0.04$ & $1.71 \pm 0.05$ \\
\hline $\begin{array}{l}\text { ITA graft diameter } \\
(\mathrm{mm})\end{array}$ & $1.82 \pm 0.04$ & $1.87 \pm 0.04$ & $1.87 \pm 0.05$ \\
\hline $\begin{array}{l}\text { Free ITA graft } \\
\quad \text { flow }(\mathrm{ml} / \mathrm{min})\end{array}$ & $93.5 \pm 6.5$ & $103.0 \pm 8.3$ & $94.8 \pm 6.4$ \\
\hline $\begin{array}{l}\text { Mean ITA graft } \\
\text { flow }(\mathrm{ml} / \mathrm{min})\end{array}$ & $34.8 \pm 3.1^{*}$ & $53.0 \pm 4.5$ & $38.3 \pm 4.9$ \\
\hline $\begin{array}{l}\text { Peak systolic ITA } \\
\text { graft flow }(\mathrm{ml} / \mathrm{min})\end{array}$ & $21.6 \pm 3.7 \dagger$ & $37.9 \pm 4.1$ & $29.4 \pm 4.1$ \\
\hline $\begin{array}{l}\text { Peak diastolic } \\
\text { ITA graft flow } \\
\text { (ml/min) }\end{array}$ & $68.6 \pm 4.6$ & $78.2 \pm 4.2$ & $69.1 \pm 7.0$ \\
\hline Diastolic fraction $(\%)$ & $76.6 \pm 2.9+$ & $65.2 \pm 2.1$ & $62.2 \pm 3.0$ \\
\hline
\end{tabular}

${ }^{*} p<0.01$ versus group 2 .

$\ddagger p<0.05$ versus group 2

$\neq p<0.01$ versus groups 2 and 3 .

from native coronary arteries into ITA grafts. Four of these eight patients showed native-dominant flow and four showed balanced flow. The four patients with type B flow profile and native-dominant flow had coronary stenosis of $50 \%$ or less, and two of them showed string sign of the ITA graft. One patient with coronary stenosis of $75 \%$ and type A flow profile showed native-dominant flow derived from a vein graft bypassed to the diagonal branch and demonstrated string sign in the ITA graft. None of the three patients who showed ITA string sign had angina or were found to have ischemia by myocardial scintigraphy. Eleven of 13 ITAs grafted to coronary arteries with stenosis of $50 \%$ or less were fully patent for the entire length. In group 2, three patients showed native-dominant flow derived from a vein graft bypassed to the diagonal branch. None of the patients in groups 2 and 3 showed string sign of the ITA graft $(p=0.089)$. All four patients with type $C$ flow profile in groups 2 and 3 showed ITA-dependent flow.

\section{Discussion}

This quantitative ultrasonic analysis of phasic blood flow in 100 ITAs grafted to coronary arteries with various degrees of stenosis showed that peak diastolic flow in ITA grafts showed no significant difference related to severity of coronary stenosis. It was also revealed that mean flow in ITAs grafted to moderately stenotic arteries was lower than that in 
those grafted to severely stenotic arteries as a result of low or reversed systolic flow. Flow in eight of 39 ITAs grafted to moderately stenotic arteries showed characteristic systolic reversal from competitive flow. Angiography at 1 month showed that string sign of the ITA graft had developed in two patients with coronary stenosis of $50 \%$ or less and to-and-fro ITA flow and in another patient with competitive flow from a diagonal vein graft. Of 13 ITAs grafted to coronary arteries with $50 \%$ or less stenosis, however, 11 did not show string sign. These results suggest that ITA grafting to coronary arteries with moderate stenosis does not predispose the patient toward string sign in the presence of substantial diastolic ITA flow.

Normal coronary artery flow is highest during diastole and decreases to nothing in early systole, when maximal myocardial compressive force develops. ${ }^{17,} 18$ Intravascular Doppler analysis of the phasic blood flow velocity within ITA grafts during cardiac catheterization revealed that the proximaldistal ITA flow patterns showed a gradual transition from a predominant systolic peak and lower diastolic peak, resembling phasic flow in the subclavian artery, to a predominant diastolic peak and lower systolic peak, resembling native coronary artery flow. ${ }^{19}$ In our study, as in previous studies ${ }^{20}$ the flow pattern in most ITAs grafted to severely stenotic arteries showed a predominant diastolic peak and lower systolic peak. The flow pattern of systolic reversal with a predominant diastolic peak was observed characteristically in ITAs grafted to moderately stenotic arteries. In these coronary arteries, systolic compressive force may expel high native coronary flow retrogradely into the ITA graft in the presence of a delay in systolic pulse pressure at the distal end of the ITA. ${ }^{21}$ This may explain why narrowing is observed at the distal segment of the ITA. Nasu and coworkers ${ }^{22}$ reported that intravascular Doppler velocimetry showed systolic reversal flow at the distal segment of the ITA grafted to the LAD coronary artery with $50 \%$ stenosis. In our study, string sign was observed only in ITAs that were grafted to moderately stenotic coronary arteries and had low flow with systolic reversal. Competitive flow from the native coronary artery is thought to be an important factor in string sign of the ITA graft, as previously reported..$^{6-9}$ If string sign of the ITA graft were related to injury, we would expect it to be more focal and to be found anywhere along the length of the graft. Histologic characteristics ${ }^{23}$ and increased contractility ${ }^{24}$ at the distal section of
Table IV. Postoperative angiographic findings of native coronary artery and ITA

\begin{tabular}{lrrrrrr}
\hline \multicolumn{1}{c}{ Angiographic findings } & $\begin{array}{c}\text { Group 1 } \\
(n=39)\end{array}$ & $\begin{array}{c}\text { Group 2 } \\
(n=34)\end{array}$ & $\begin{array}{c}\text { Group 3 } \\
(n=27)\end{array}$ \\
\hline Stenosis at ITA anastomosis & 2 & 5 & 0 & 0 & 1 & 4 \\
Patterns of distal LAD & & & & & & \\
$\quad$ coronary artery flow & & & & & & \\
$\quad$ Native-dominant flow & 6 & 15 & 3 & 9 & 0 & 0 \\
Balanced flow & 24 & 62 & 10 & 29 & 1 & 4 \\
$\quad$ ITA-dependent flow & 9 & 23 & 21 & 62 & 26 & 96 \\
String sign of ITA graft & 3 & 8 & 0 & 0 & 0 & 0 \\
\hline
\end{tabular}

the ITA could also be responsible for string sign of the ITA graft.

ITA flow decreased from $47 \mathrm{ml} / \mathrm{min}$ before operation to $35 \mathrm{ml} / \mathrm{min}$ after grafting to coronary arteries with moderate stenosis. Adaptation to decreased flow proceeds more rapidly than response to increased flow. Diameter changes are completed within 2 weeks after flow rates are decreased. ${ }^{25}$ The rapid response of reduction in arterial diameter to decreased flow can be caused by vasomotor factors alone and is considered endothelium dependent. ${ }^{26}$ Carrel and colleagues reported the cases of 45 patients who received ITA grafts and then received additional saphenous vein grafts because of ITA malperfusion. Early postoperative angiography $(<8$ weeks) revealed widely patent ITAs and patent vein grafts in $48 \%$ and narrowed ITA grafts and patent vein grafts in $40 \%$; patent vein grafts and nonvisualized ITAs were found in $9 \%$. Late angiographic results (12 to 24 months) showed widely patent ITA grafts and patent vein grafts in $57 \%$, narrowed ITA grafts and patent vein grafts in $36 \%$, and patent vein grafts and nonvisualized ITA grafts in $7 \%$. No major differences were found between early and late angiograms. We considered angiography 1 month after the operation appropriate for assessing the influence of hemodynamics on the patency of ITA grafts. It is not known whether sustained vasomotor response inevitably gives rise to subsequent remodeling of the arterial wall. Our study showed that 11 of 13 ITAs grafted to coronary arteries with stenosis of $50 \%$ or less were fully patent along the entire length, and only two of them showed string sign. ITA grafting for coronary arteries with noncritical stenosis did not cause a high incidence of string sign. Sheer stress has been implicated in vascular remodeling. ${ }^{28}$ It is tempting to hypothesize that significant sheer stress caused by high diastolic peak flow might prevent string sign in the ITA graft.

The ITA was preferentially grafted to the most 
important coronary artery, the LAD coronary artery, because of its excellent long-term patency. When the LAD coronary artery shows noncritical stenosis, we must consider whether the artery should undergo ITA grafting. Wide patency along the entire length of the graft is important. In early experience with ITA grafting, Barner ${ }^{6}$ noted an $11 \%$ prevalence of distal narrowing in the ITA graft at 1-year postoperative angiography. All grafts that showed narrowing had been normal at angiography 1 week after operation. The incidence of ITA narrowing decreased thereafter to $2 \% .^{29} \mathrm{~A}$ similar incidence was observed by Geha and Baue, ${ }^{7}$ and a noncritical lesion in the coronary artery was considered a contraindication for ITA grafting. Seki and coworkers $^{9}$ reported that $9.5 \%$ of ITAs grafted to LAD coronary arteries showed string sign or were occluded and that most of these ITA grafts had been bypassed to coronary arteries with stenosis of $50 \%$ or less. Cosgrove and associates ${ }^{3}$ reported that ITAs grafted to coronary arteries with stenosis of less than $50 \%$ had a $92.3 \%$ patency rate, which was similar to the rate of $96.3 \%$ for ITAs grafted to coronary arteries with greater than $50 \%$ stenosis. They did not observe string sign in the ITA graft in 13 patients who later underwent catheterization. Urschel and colleagues ${ }^{30}$ reported that intraoperative angioplastic dilation of native lesions proximal to ITA grafts had no apparent adverse effects on graft patency 1 to 7 years later, despite the increase in competing flow. In a discussion of Cosgrove and associates' work, ${ }^{3}$ Flemma reported the cases of two patients in whom both ITA and saphenous vein bypass grafts were placed on the LAD coronary artery. The ITA graft atrophied and was just a string for its entire length on further follow-up. In a similar situation, ITA and vein grafts may be placed on the same coronary artery system. In our studies, nine patients received an ITA graft to the LAD coronary artery and also a vein graft to its diagonal branch; there was no obstruction between the two, and one patient showed string sign of the ITA graft. ITA grafts with string sign have been sporadically reported to retain recruitable patency for the long $^{29}$ or short term. ${ }^{31}$ It is not clear whether recruitable patency is a common finding or whether most ITA grafts with string sign show subsequent graft closure.

We conclude that ITA grafting for the LAD coronary artery with moderate stenosis is acceptable. There was not a high incidence of string sign of the ITA, and the graft did not harm the native coronary artery. Analyses of phasic blood flow in
ITAs grafted to coronary arteries with stenosis of $50 \%$ or less suggest good ITA function, although these are only 1 -month results, and we cannot recommend prophylactic ITA grafting until further studies of longer duration have demonstrated its beneficial influence on CABG.

\section{REFERENCES}

1. Campeau L, Lesperance J, Herman J, Corbara F, Grondin CM, Bourassa MG. Loss of the improvement of angina between 1 and 7 years after coronary bypass surgery: correlations with changes in vein grafts and coronary arteries. Circulation 1979;60:(Suppl 1):I1-5.

2. Bruschke AV, Wijers TS, Kolsters W, Landmann J. The anatomic evolution of coronary artery disease demonstrated by coronary arteriography in 256 nonoperated patients. Circulation 1981;63:527-36.

3. Cosgrove DM, Loop FD, Saunders CL, Lytle BW, Kramer JR. Should coronary arteries with less than fifty percent stenosis be bypassed? J Thorac Cardiovasc Surg 1981;82:52030.

4. Loop FD, Lytle BW, Cosgrove DM, Stewart RW, Goormastic M, Williams GW, et al. Influence of the internal-mammary-artery graft on 10-year survival and other cardiac events. $\mathrm{N}$ Engl J Med 1986;314:1-6.

5. Lytle BW, Loop FD, Cosgrove DM, Taylor PC, Goormastic $M$, Peper W, et al. Fifteen hundred coronary reoperation: results and determinants of early and late survival. J Thorac Cardiovase Surg 1987;93:847-59.

6. Barner HB. Double internal mammary-coronary artery bypass. Arch Surg 1974;109:627-30.

7. Geha AS, Baue AE. Early and late results of coronary revascularization with saphenous vein and internal mammary artery grafts. Am J Surg 1979;137:456-63.

8. Ivert T, Huttenen K, Landou C, Björk VO. Angiographic studies of internal mammary artery grafts 11 year after coronary artery bypass grafting. J Thorac Cardiovasc Surg 1988;96:1-12

9. Seki T, Kitamura S, Kawachi K, Morita R, Kawata T, Mizuguchi $\mathrm{K}$, et al. A quantitative study of postoperative luminal narrowing of the internal thoracic artery graft in coronary artery bypass surgery. J Thorac Cardiovasc Surg 1992;104:1532-8.

10. Sarabu MR, McClung JA, Fass A, Reed GE. Early postoperative spasm in left internal mammary artery bypass graft. Ann Thorac Surg 1987;44:199-200.

11. Mills NL, Ochsner JL. Technique of internal mammary-tocoronary artery bypass. Ann Thorac Surg 1974;17:237-46.

12. Spence PA, Lust RM, Zeri RS, Jolly SR, Mehta PM, Otaki $\mathrm{M}$, et al. Competitive flow from a fully patent coronary artery does not limit acute mammary graft flow. Ann Thorac Surg 1992;54:21-6

13. Lust RM, Zeri RS, Spence PA, Hopson SB, Sun YS, Otaki $M$, et al. Effect of chronic native flow competition on internal thoracic artery grafts. Ann Thorac Surg 1994;57:45-50.

14. Takemura H, Kawasuji M, Sakakibara N, et al. Quantitative hemodynamic assessment of internal thoracic artery grafts using transthoracic duplex imaging. J Jpn Assoc Thorac Surg 1994;42:2171-7.

15. Barnes RJ, Comline RS, Dobson A, Drost CJ. An implant- 
able transit-time ultrasonic blood flow meter. J Physiol 1983;345:2-3.

16. Austen WG, Edwards JE, Frye RI, et al. AHA committee report: a reporting system on patients evaluated for coronary artery disease: report of the Ad Hoc Committee for Grading of Coronary Artery Disease, Council on Cardiovascular Surgery, American Heart Association. Circulation 1975;51: (Suppl): 7-40.

17. Marcus M, Wright C, Doty D, Eastham C, Laughlin D, Krumm $P$, et al. Measurements of coronary velocity and reactive hyperemia in the coronary circulation of humans. Circ Res 1981;49:877-91.

18. Kajiya F, Tsujioka K, Ogasawara Y, Wada Y, Matsuoka S, Kanazawa $S$, et al. Analysis of flow characteristics in poststenotic regions of the human coronary artery during bypass graft surgery. Circulation 1987;76:1092-100.

19. Bach RG, Kern MJ, Donohue TJ, Aguirre FV, Caracciolo EA. Comparison of phasic blood flow velocity characteristics of arterial and venous coronary artery bypass conduits. Circulation 1993;88(5 Pt 2):133-140.

20. Bandyk DF, Galbraith TA, Haasler GB, Almassi GH. Blood flow velocity of internal mammary artery and saphenous vein grafts to the coronary arteries. J Surg Res 1988;44:342-51.

21. Tedoriya T, Kawasuji M, Ueyama K, Sakakibara N, Takemura H, Watanabe Y. Physiologic characteristics of coronary artery bypass grafts. Ann Thorac Surg 1993;56:951-6.

22. Nasu M, Akasaka T, Okazaki T, et al. Postoperative flow characteristics of left internal thoracic artery grafts. Ann Thorac Surg 1995;59:154-62.
23. van Son JA, Smedt F. Bifurcated ("Y") internal thoraciccoronary artery grafts [letter]. J Thorac Cardiovasc Surg 1993;106:945-6.

24. He GW. Contractility of the human internal mammary artery at the distal section increases toward the end. J Thorac Cardiovasc Surg 1993;106:406-11.

25. Langille BL, Bendeck MP, Keeley FW. Adaptations of carotid arteries of young and mature rabbits to reduced carotid blood flow. Am J Physiol 1989;256(4 Pt 2):H931-9.

26. Langille BL, O'Donnell $\mathrm{F}$. Reductions in arterial diameter produced by chronic decreases in blood fiow are endothelium-dependent. Science 1986;231:405-7.

27. Carrel T, Kujawski T, Zund G, et al. The internal mammary artery malperfusion syndrome: incidence, treatment and angiographic verification. Eur J Cardiothorac Surg 1995;9: 190-7.

28. Glagov S, Zarius C, Giddens DPO, Ku DN. Hemodynamics and atherosclerosis. Arch Pathol Lab Med 1988;112:1018-31.

29. Dincer B, Barner HB. The "occluded" internal mammary artery graft: restoration of patency after apparent occlusion associated with progression of coronary disease. J Thorac Cardiovasc Surg 1983;85:318-20.

30. Urschel HC Jr, Razzuk MA, Miller E, Chung SY. Operative transluminal balloon angioplasty. $\mathbf{J}$ Thorac Cardiovase Surg 1990;99:1-9.

31. Kitamura S, Kawachi K, Seki T, Sawabata N, Morita R, Kawata T. Angiographic demonstration of no-flow anatomic patency of internal thoracic-coronary artery bypass grafts. Ann Thorac Surg 1992;53:156-9.

\section{Availability of Journal back issues}

As a service to our subscribers, copies of back issues of The Journal of Thoracic and Cardiovascular Surgery for the preceding 5 years are maintained and are available for purchase from Mosby at a cost of $\$ 13.50$ per issue until inventory is depleted. The following quantity discounts are available: $25 \%$ off on quantities of 12 to 23 , and one third off on quantities of 24 or more. Please write to Mosby-Year Book, Inc., Subscription Services, 11830 Westline Industrial Drive, St. Louis MO 63146-3318, or call 800-453-4351 or 314-453-4351 for information on availability of particular issues. If unavailable from the publisher, photocopies of complete issues may be purchased from UMI, 300 N. Zeeb Rd., Ann Arbor, MI 48106, 313-761-4700. 